\title{
Report of Nineteen Cerebral Vein Thrombosis Referrals to an Emergency Department a Case Series and Literature Review
}

\author{
Hosein Delavar Kasmaei ${ }^{1}$; Alireza Baratloo ${ }^{2, *}$; Zahra Nasiri ${ }^{1}$; Maryam Soleymani ${ }^{1}$; Ali \\ Shirafkan ${ }^{3}$; Zahra Sadat Hamedi ${ }^{4}$ \\ ${ }^{1}$ Department of Neurology, Shohadaye Tajrish Hospital, Shahid Beheshti University of Medical Sciences, Tehran, IR Iran \\ ${ }_{2}^{2}$ Department of Emergency Medicine, Shohadaye Tajrish Hospital, Shahid Beheshti University of Medical Sciences, Tehran, IR Iran \\ ${ }^{3}$ Department of Surgery, University of Texas Medical Branch, Galveston, Texas, USA \\ ${ }^{4}$ Department of Medicine, Shahid Beheshti University of Medical Sciences, Tehran, IR Iran \\ *Corresponding author: Alireza Baratloo, Department of Emergency Medicine, Shohadaye Tajrish Hospital, Shahid Beheshti University of Medical Sciences, Tehran, IR Iran. Tel: +98- \\ 9122884364, Fax:+98-2122721155, E-mail: alirezabaratloo@yahoo.com
}

Received: May 24, 2014; Revised: Jun 15, 2014; Accepted: Jun 15, 2014

Background: Risk factors, diagnosis, treatment and outcome of patients with cerebral venous thrombosis (CVT) have always been challenging.

Objectives: The present study aimed to report on the characteristics of CVT in the patients referring to the emergency unit of a teaching hospital to review and add to the current knowledge on this topic.

Patients and Methods: This was a retrospective cross sectional study, which consisted of a series of 19 patients admitted to the emergency department during one year with the diagnosis of CVT. The required data were extracted from existing reports in the case files via manualsearching. All patients were re-evaluated prospectively with the goal of outcome assessment.

Results: This study included 19 patients with CVT. Mean age of the cases was $38.7 \pm 8.8$ years (range 22 to 62 years) and they were predominantly women $(84.2 \%)$. The most common chief complaint at presentation was headaches, observed in 15 (78.9\%) of the patients either solely or accompanied with other symptoms. Use of oral contraceptive pills (OCPs) was reported in more than half of the cases. The outcome was favorable in 18 (94.7\%) of the cases and only one patient, despite appropriate five months of remedial measures, still suffered from visual disturbance.

Conclusions: Although many risk factors for CVT have been identified thus far, it seems that there are different patterns of frequency among ethnic groups. Thus, an inter racial comparison study is still needed. Likewise, with attention to the lack of proper studies and strong evidence regarding treatment options, conducting a multicenter prolonged study with a large sample size is apparently required.

Keywords:Risk Factor; Diagnosis; Intracranial Thrombosis; Case Management

\section{Background}

Cerebral venous thrombosis (CVT) is an uncommon disorder affecting predominantly younger women (13). Despite numerous studies conducted around the world, various aspects of patients with CVT including risk factors, diagnosis, treatment and outcome remains challenging. Thus CVT still poses major problems in the emergency room setting (4). Patients with CVT present a remarkably wide spectrum but non-specific signs and symptoms including headaches, seizures, hemiparesis, focal lateralized neurological signs, papilledema and behavioral symptoms such as delirium, amnesia and disturbances in consciousness, which may fluctuate over days. These, all count as other clinical manifestations that can be found depending on the mechanisms of the injury and anatomical location of the lesions (4-6).

\section{Objectives}

Considering all above-mentioned information, it is necessary to increase knowledge and review the details of CVT risk factors, manifestations, imaging findings and outcomes. Therefore, the present study was conducted to report on the characteristics of CVT in patients, who had referred to the emergency unit of a hospital.

\section{Materials and Methods}

In this retrospective cross-sectional case series we evaluated all consecutive patients admitted to the emergency department of Shohadaye Tajrish Hospital, an educational medical center in northern Tehran, Iran from January 2013 to December 2013. All cases were diagnosed with CVT confirmed with magnetic resonance imaging (MRI) and magnetic resonance venography (MRV). Demographic data, chief complaint and symptoms that lead to the impression of an underlying CVT were identified retrospectively by reviewing case files. The medical and drug history, possible risk factors and neurological physical ex-

Copyright (C) 2014, Tehran University of Medical Sciences; Published by Kowsar Corp. This is an open-access article distributed under the terms of the Creative Commons Attribution License, which permits unrestricted use, distribution, and reproduction in any medium, provided the original work is properly cited. 
amination were analyzed considering the findings which led to the suspicion of CVT. Further, thrombus localization and the presence of venous infarcts were registered. Thrombus locations were distinguished based on the existing radiologist reports, prospectively reviewed and confirmed by a neuroimaging specialist. Data collection was performed by a manual search.

All patients were treated by unfractured heparin (manufactured by Alborz Daru Company) with 100 unit/kg as the bolus intravenous dose and 1000 unit/hr intravenous infusion almost after diagnosis confirmation with MRV imaging until appearance of disruption in partial thromboplastin time (PTT) test. Oral warfarin (manufactured by Orion Pharma Company) was administered with a dosage of $5 \mathrm{mg} /$ day at second day of admission and was continued for at least six months. All patients were called for re-examination and re-evaluation in March 2014 with the goal of outcome assessment. Resolving the chief complaints and also positive physical examination findings in re-evaluation was considered as favorable outcomes. Data were registered in the database designed for this purpose and analyzed with SPSS 21.

\section{Results}

During the period of the study, we identified 19 patients with mean age of $38.7 \pm 8.8$ years (range: $22-62$ ) predominantly consisting of females (84.2\%) with most referrals during the hot summer season (8 of 19 (42.1\%)). Among these candidates, three patients (15.8\%) presented more than one symptom and the other 16 had only one symptom. Demographic data, chief complaint, other symptoms, medical history and physical examination findings are summarized in Table 1 . Anatomical locations of the thrombus are listed in Table 2 ; this information was extracted based on the candidates existing radiologist reports, reviewed and confirmed by a neuroimaging specialist. Superior sagittal and right transverse sinuses were the most commonly involved. Multiple sinuses were involved in five patients (26.3\%). Their details are presented separately in Table 3.

After reviewing the radiologist reports on all brain computed tomography scans, it became clear that eight out of 19 cases (42.1\%) had abnormalities possibly involving CVT while the other 11 (57.9\%) had normal radiologist reports on this type of imaging. In one of the above mentioned abnormal brain CT scans, bilateral thalamus infarct was reported which is considered as a rare presentation for CVT. Among these patients, there were four cases with confusing hemorrhagic patterns in their brain computed tomography scans. Their details are presented separately in Table 4 . Between these cases, four of 19 (21\%) did not have headaches neither as the chief complaint nor in detailed history of present illness. Their details are presented separately in Table 5.

Use of oral contraceptive pills (OCPs), which is currently considered as an important and prevalent risk factor, was reported in more than half of the cases (10 of 19 cas- es (52.6\%)). Mean follow up period was $6.9 \pm 2.9$ months (range 4 to 12 months). One of the patients, a 37-year-old female with diagnosis of right transverse sinus thrombosis, was suffering from visual disturbance for a period of five months at time of re-evaluation despite appropriate remedial measures. Finally 18 from 19 patients had favorable outcomes and multinomial logistic regression test showed effectiveness of therapeutic intervention ( $P$ $=0.005)$. There were no reports regarding hospital mortalities resulting from CVT. Surprisingly, all patients had no disturbances on their follow up conducted laboratory tests.

\begin{tabular}{lc}
\hline \multicolumn{1}{l}{ Table 1. Details of Cerebral Vein Thrombosis Patients ${ }^{\mathrm{a}}$} \\
\hline Variables & Values \\
\hline Gender & $16(84.2 \%)$ \\
\hline Female & $3(15.8 \%)$ \\
\hline Male & \\
\hline Chief complaint & $15(78.9 \%)$ \\
\hline Headache & $2(10.5)$ \\
\hline Hemiparesis & $1(5.2 \%)$ \\
\hline Altered mental status & $2(10.5)$ \\
\hline Seizer & $2(10.5)$ \\
\hline Visual disturbance & \\
\hline Medical history & $2(10.5)$ \\
\hline Hypertension & $1(5.2 \%)$ \\
\hline Colorectal cancer & $1(5.2 \%)$ \\
\hline Hypothyroidism & $11(57.9 \%)$ \\
\hline Physical examination & $5(26.3 \%)$ \\
\hline Papilla edema & $8(42.1 \%)$ \\
\hline Nerve palsies & \\
\hline Visual field deficit & \\
\hline Data & \\
\hline
\end{tabular}

a Data are Presented as No. (\%).

\begin{tabular}{|lc|}
\hline Table 2. Thrombus Location Distribution & \\
\hline Thrombus Location & Values \\
\hline Superior sagittal & $7(28 \%)$ \\
\hline Right transverse & $7(28 \%)$ \\
\hline Left transverse & $6(24 \%)$ \\
\hline Right sigmoid & $2(8 \%)$ \\
\hline Inferior sagittal & $1(4 \%)$ \\
\hline Left straight & $1(4 \%)$ \\
\hline Left trolard & $1(4 \%)$ \\
\hline
\end{tabular}

a Data are Presented as No. (\%). 
Delavar Kasmaei H et al.

\begin{tabular}{|c|c|c|c|c|c|c|c|}
\hline Cases & Gender & Age, $y$ & Chief Complaint & Medical History & OCP or Hormone Use & Physical Examination & Thrombus Location \\
\hline $\mathbf{1}$ & Female & 30 & Headache & Negative & Positive & $\begin{array}{l}\text { Papilla edema, visual } \\
\text { field deficits }\end{array}$ & $\begin{array}{l}\text { Superior sagital, right } \\
\text { transverse }\end{array}$ \\
\hline 2 & Female & 41 & Headache & Negative & Positive & Papilla edema & $\begin{array}{l}\text { Right sigmoid, right } \\
\text { transverse }\end{array}$ \\
\hline 3 & Female & 41 & Headache & Negative & Positive & Negative & $\begin{array}{l}\text { Superior sagital, left } \\
\text { transverse }\end{array}$ \\
\hline 4 & Female & 37 & Headache & Negative & Negative & Nerve palsies & $\begin{array}{l}\text { Superior sagital, } \\
\text { inferior sagittal }\end{array}$ \\
\hline 5 & Female & 44 & $\begin{array}{l}\text { Headache, visual } \\
\text { disturbance }\end{array}$ & Negative & Positive & $\begin{array}{l}\text { Papilla edema, visual } \\
\text { field deficits }\end{array}$ & $\begin{array}{l}\text { Left straight, left } \\
\text { transverse }\end{array}$ \\
\hline
\end{tabular}

Table 4. Details of Patients With a Hemorrhagic Pattern in Brain Computed Tomography Scan

Cases Gender Age, y Chief Complaint Medical History OCP or Hormone Use Physical Examination Thrombus Location

\begin{tabular}{lccccccc}
\hline $\mathbf{1}$ & Female & 42 & Headache & Negative & Negative & $\begin{array}{c}\text { Papilla edema, nerve } \\
\text { palsies, visual field } \\
\text { deficits }\end{array}$ & Left trolard \\
$\mathbf{2}$ & Female & 22 & $\begin{array}{c}\text { Headache, altered } \\
\text { mental status }\end{array}$ & Negative & Positive & Nerve palsies & Superior sagital \\
$\mathbf{4}$ & Female & 38 & Headache & Negative & Negative & $\begin{array}{c}\text { Papilla edema, visual } \\
\text { field deficits }\end{array}$ & Right transverse \\
\hline
\end{tabular}

Table 5. Details of Patients Without Headaches

Cases Gender Age, y Chief Complaint Medical History OCP or Hormone Use Physical Examination Thrombus Location

\begin{tabular}{lccccccc}
\hline $\mathbf{1}$ & Female & 47 & Hemiparesis & Negative & Positive & Nerve palsies & Superior sagital \\
$\mathbf{2}$ & Male & 41 & Seizer & Colorectal cancer & Negative & Papilla edema & Right transverse \\
$\mathbf{3}$ & Female & 37 & Visual disturbance & Negative & Negative & $\begin{array}{c}\text { Papilla edema, visual } \\
\text { field deficits }\end{array}$ & Right transverse \\
$\mathbf{4}$ & Female & 35 & $\begin{array}{c}\text { Seizer, } \\
\text { hemiparesis }\end{array}$ & Negative & Positive & Nerve palsies & $\begin{array}{c}\text { Superior sagital, left } \\
\text { transverse }\end{array}$ \\
\hline
\end{tabular}

\section{Discussion}

\subsection{Presentation}

No set of symptoms has adequate sensitivity or specificity for dealing with the possible diagnosis of CVT, yet headaches plus papilledema, headaches plus diplopia, headaches plus seizure and focal neurological deficit plus papilledema have been mentioned in previous literature as suggestive combinations (4). The clinical presentation of CVT can be highly variable and usually defined by two mechanisms: 1) increased intracranial pressure due to impaired venous drainage 2) focal brain injury caused by venous ischemia/infarction or hemorrhage. Almost always, both mechanisms are involved in the patient's clinical findings, either at presentation or later in the course of the disease. Location and size of the lesion may also affect the type of symptoms. Headache, as an indication for increased intracranial pressure, is the most prevalent symptom and often has a vague and progressive pattern solely or in combination with other symptoms (7). However, thunderclap headache mimicking subarachnoid hemorrhage and migrainous type has also been reported. Seizure accompanied with focal findings consistent with stroke is rare and highly suggestive of CVT; this is frequently seen with sagittal sinus and cortical veins thrombosis (8-10)

Sensory deficits are less frequent but on the other hand, motor weaknesses including hemiparesis is the most common focal finding. Aphasia resulting from left transverse sinus thrombosis and psychosis, in conjunction with focal neurological signs, has also been reported $(4,11,12)$. Thrombosis of the straight sinus and its related branches, large venous infarcts, parenchymal hemorrhages and presence of extensive cerebral edema are possible risk factors for encephalopathy. Elderly in 
contrast with younger patients are more likely to present an altered mental status (13). In our study, consistent with previous reports, headache was the most prevalent symptom as solely the primary presentation or in combination with other symptoms.

\subsection{Risk Factors}

Predisposing causes of CVT are numerous and can be categorized in the manner summarized in Table $6(3,7$, 13-15). Based on the current evidence, inherited thrombophilia, use of oral contraceptives and hyperhomocysteinemia are well-known and more prevalent risk factors than the others $(7,12)$. Considerable numbers of non-pregnant women with the diagnosis of CVT were using oral contraceptive pills, so it is clear that the use of these agents is associated with an increased risk and this risk is greater if accompanied with the presence of hereditary prothrombotic factors $(3,7)$. In contrast with numerous confirmative data $(3,7,14,16)$, in rare published manuscripts, like the one belonging to Youssef Sidhom et al. that was conducted on Tunisian patients, thrombophilia, infections, and postpartum state were also mentioned as prominent risk factors, but oral contraceptive use was not a major risk factor in the studied population (17). Akihiro Shindo et al. also found that CVT in Japanese patients is frequently associated with heredity thrombophilia and protein $S$ gene mutation (12). In our study, consistent with some other studies conduct- ed in Iran, oral contraceptives use was an undeniable risk factor.

\subsection{Diagnosis}

Diagnosis can be made from brain computed tomography (CT) scans that may demonstrate venous infarcts or its specific hemorrhages or alternatively allow detection of a different diagnosis. The CVT should be suspected in the setting of multiple hemorrhagic infarctions in one hemisphere without a source of embolism or atherothrombosis or in multiple infarctions on both sides $(5,18)$. However it has poor sensitivity and shows direct signs of cerebral venous thrombosis in less than half of the cases (7).

No one can rule out CVT with a normal plain brain CT or MRI, and venographic imaging should always be performed in probable cases, while it may also help distinguish normal anatomic variants like hypoplastic sinus (Class I; level of evidence C) (7, 14). The AHA/ASA 2011 Scientific Statement recommends magnetic resonance (MR) with T2 weighted imaging and MR venography as the imaging test of choice for evaluation of suspected cerebral-venous thrombosis. It is also suggested that Gradient echo T2 susceptibility weighted images accompanied with other sequences may promote the accuracy of diagnosis (Class II a; level of evidence B) (7, 18-20). CVT imaging findings on MRI in acute, subacute and chronic phases are summarized in Table $7(7,8)$.

\begin{tabular}{|c|c|}
\hline Categories & Subtypes \\
\hline \multirow[t]{2}{*}{ Thrombophilia } & Inherited, (Deficiencies of antithrombin III, protein C, and protein S; Factor V Leiden mutation) \\
\hline & Acquired, (Antiphospholipid and anticardiolipin antibodies, Hyperhomocysteinemia) \\
\hline \multirow[t]{3}{*}{ Women's health concerns } & Pregnancy \\
\hline & Postpartum state \\
\hline & Hormonal contraceptive use \\
\hline \multirow[t]{2}{*}{ Infectious disorders } & Localized, (Otitis, Mastoiditis, Sinusitis, Meningitis) \\
\hline & Systemic \\
\hline \multirow[t]{2}{*}{ Chronic inflammatory diseases } & Vasculitides, (Systemic lupus erythematosus behcet disease) \\
\hline & Inflammatory bowel disease \\
\hline \multirow[t]{5}{*}{ Hematologic disorders } & Polycythemia \\
\hline & Thrombocythemia \\
\hline & Iron deficiency anemia \\
\hline & Essential thrombocytosis \\
\hline & Paroxysmal nocturnal hemoglobinuria \\
\hline \multirow[t]{5}{*}{ Trauma } & Local injury to cerebral sinuses or veins \\
\hline & Jugular venous cannulation \\
\hline & Neurosurgical procedures \\
\hline & Lumbar puncture \\
\hline & Head trauma \\
\hline Nephrotic syndrome & - \\
\hline Malignancy & - \\
\hline
\end{tabular}


Delavar Kasmaei H et al.

Table 7. Magnetic Resonance Imaging Finding of Cerebral Venous Thrombosis in Various Phases of the Disease

\begin{tabular}{lcc}
\hline Phase Type & T1-Weighted & T2-Weighted \\
\hline Acute phase & Isointense & Hypointense \\
Sub-acute phase & Hyperintense & Hyperintense \\
Chronic phase & Heterogeneous with variable intensity & Heterogeneous with variable intensity \\
\hline
\end{tabular}

\subsection{Management}

In suspected patients with CVT diagnosis, blood samples should be send for assessing complete blood count, chemistry panel, prothrombin time (PT), and activated partial thromboplastin time (aPTT) (Class I; level of evidence C) (7). Evaluation for deficiencies of protein C, S, and antithrombin in the acute phase and during treatment with warfarin usually leads to negative results and should preferably be delayed until 2 to 4 weeks after completion of anticoagulation (6, 21-23).

Initial anticoagulation with unfractured heparin (UFH) or low molecular weight heparin (LMWH) in full anticoagulant doses is the only proven therapy for patients with CVT that should be followed, regardless of the presence of Intra cranial hemorrhage (ICH) (Class II a; Level of Evidence B) $(7,24)$. Appropriate anticoagulation is generally not accompanied by any additional risk of intra cranial hemorrhage (5). In patients with severe involvement of multiple sinuses and veins, anticoagulation alone has limited effects on the lysis of deep cerebral venous thrombosis, thus thrombolytic therapy combined with anticoagulation may be more effective $(18,25,26)$.

Due to the lack of randomized controlled trials with the aim of assessing the proper anticoagulation period for CVT treatment, guidelines should be prepared based on the evidences and recommendations for other venous thromboembolism (VTE) such as deep vein thrombosis and pulmonary embolism. The AHA/ASA 2011 Scientific Statement recommends anticoagulation with a target international normalized ratio (INR) of 2.0 to 3.0 for 3 to 6 months following the acute phase for patients with the first time CVT without any known risk factors and 6 to 12 months for those with severe coagulopathy or recurrent CVT $(7,24)$.

Women with a history of oral contraceptive pills use should be recommended for alternative non-estrogen based contraception methods. Women with a history of CVT while receiving hormonal contraceptive, who presented symptoms during pregnancy or the postpartum period, are at additional risk of recurrence during the next pregnancies. The low-molecular-weight heparin (LMWH) as a prophylactic agent is often recommended during future same courses. The AHA/ASA 2011 Scientific Statement recommends follow up imaging to evaluate recanalization 3 to 6 months after treatment initiation (7, 14). In the case of clinical deterioration, despite intensive anticoagulation treatment, local thrombolysis and mechanical thrombectomy may be considered, yet clinical efficacy is supported only by case reports (Class II b; level of evidence C) $(7,24)$.

\subsection{Outcome}

Early diagnosis and prompt appropriate treatment are usually associated with a good prognosis, but the scarcity and various manifestations of CVT may lead to delay in the treatment initiation. Rare numbers of hemorrhagic cases that are often misdiagnosed as intracranial hemorrhage contribute to such delays. Markedly decreased levels of consciousness on presentation, hemorrhagic pattern on primary brain CT scan, delay in diagnosis and therefore in treatment, are poor prognostic factors $(5,25,27,28)$.

Also, many risk factors are known today but it seems that there is different ethnic frequency patterns and inter-racial comparison studies are still needed. Likewise with attention to the lack of proper studies and strong evidence in the field of treatment options, conducting a multicenter prolonged study with a large sample size is apparently required.

\section{Acknowledgements}

We would like to express our special thanks to the Emergency and Neurology Department staff of Shohadaye Tajrish Hospital. This work was part of the academic thesis of Dr Zahra Sadat Hamedi, conducted at Shahid Beheshti University of Medical Sciences.

\section{Authors' Contributions}

Study conception and design: Alireza Baratloo and Hosein Delavar Kasmaei. Data collection: Zahra Nasiri, Maryam Soleymani and Zahra Sadat Hamedi. Statistical analyses and drafting of the manuscript: Alireza Baratloo and Zahra Sadat Hamedi. All authors were involved in the analysis and interpretation of the results. Alireza Baratloo and Ali Shirafkan revised the manuscript critically for important intellectual content and were involved in drafting the manuscript. All authors read and approved the final manuscript.

\section{Funding/Support}

All authors declare that this study was accomplished without any funding or support and the authors are responsible for all expenses.

\section{References}

1. Coutinho JM, Ferro JM, Canhao P, Barinagarrementeria F, Cantu 
C, Bousser MG, et al. Cerebral venous and sinus thrombosis in women. Stroke j cerebral circulation. 2009;40(7):2356-61.

2. Weimar C, Masuhr F, Hajjar K. Diagnosis and treatment of cerebral venous thrombosis. Expert Rev Cardiovasc Ther. 2012;10(12):1545-53.

3. Baratloo A, Safari S, Rouhipour A, Hashemi B, Rahmati F, Motamedi M, et al. The Risk of Venous Thromboembolism with Different Generation of Oral Contraceptives; a Systematic Review and Meta-Analysis. Emergency. 2014;2(1):1-11.

4. Tanislav C, Siekmann R, Sieweke N, Allendorfer J, Pabst W, Kaps M, et al. Cerebral vein thrombosis: clinical manifestation and diagnosis. BMC Neurol. 2011;11:69.

5. Kasmaei HD, Baratloo A, Soleymani M. A 33-year-old woman with severe postpartum headache. Emergency. 2013;1(1):27-9.

6. Das SK, Banerjee N, Khaskil S, Mukhopadhyay S. Extensive cortical venous thrombosis associated with protein $S$ deficiency and hyperhomocysteinaemia. J Indian Acad Clin Med. 2014;15(1):65-7.

7. Saposnik G, Barinagarrementeria F, Brown RD, Jr, Bushnell CD, Cucchiara B, Cushman M, et al. Diagnosis and management of cerebral venous thrombosis: a statement for healthcare professionals from the American Heart Association/American Stroke Association. Stroke j cerebral circulation. 2011;42(4):1158-92.

8. Ferro JM, Canhao P, Bousser MG, Stam J, Barinagarrementeria F, Iscvt Investigators . Early seizures in cerebral vein and dural sinus thrombosis: risk factors and role of antiepileptics. Stroke. 2008;39(4):1152-8.

9. Cumurciuc R, Crassard I, Sarov M, Valade D, Bousser MG Headache as the only neurological sign of cerebral venous thrombosis: a series of 17 cases. J Neurol Neurosurg Psychiatry. 2005;76(8):1084-7.

10. Crassard I, Bousser MG. [Headache in patients with cerebral venous thrombosis]. Rev Neurol (Paris). 2005;161(6-7):706-8.

11. Ferro JM, Canhao P, Stam J, Bousser MG, Barinagarrementeria F, Iscvt Investigators . Prognosis of cerebral vein and dural sinus thrombosis: results of the International Study on Cerebral Vein and Dural Sinus Thrombosis (ISCVT). Stroke j cerebral circulation. 2004;35(3):664-70.

12. Shindo A, Wada H, Ishikawa H, Ito A, Asahi M, Ii Y, et al. Clinical features and underlying causes of cerebral venous thrombosis in Japanese patients. Int J Hematol. 2014;99(4):437-40.

13. Ferro JM, Canhao P, Bousser MG, Stam J, Barinagarrementeria F, Iscvt Investigators . Cerebral vein and dural sinus thrombosis in elderly patients. Stroke j cerebral circulation. 2005;36(9):1927-32.

14. Piazza G. Cerebral venous thrombosis. Circulation. 2012; 125(13):1704-9.
15. Coutinho JM, Zuurbier SM, Aramideh M, Stam J. The incidence of cerebral venous thrombosis: a cross-sectional study. Stroke $j$ cerebral circulation. 2012;43(12):3375-7.

16. Geisbusch C, Lichy C, Richter D, Herweh C, Hacke W, Nagel S. [Clinical course of cerebral sinus venous thrombosis. Data from a monocentric cohort study over 15 years]. Nervenarzt. 2014;85(2):211-20.

17. Sidhom Y, Mansour M, Messelmani M, Derbali H, Fekih-Mrissa $\mathrm{N}$, Zaouali J, et al. Cerebral venous thrombosis: clinical features, risk factors, and long-term outcome in a Tunisian cohort. J Stroke Cerebrovasc Dis. 2014;23(6):1291-5.

18. Rizzo L, Crasto SG, Ruda R, Gallo G, Tola E, Garabello D, et al. Cerebral venous thrombosis: role of CT, MRI and MRA in the emergency setting. Radiol Med. 2010;115(2):313-25.

19. Leach JL, Fortuna RB, Jones BV, Gaskill-Shipley MF. Imaging of cerebral venous thrombosis: current techniques, spectrum of findings, and diagnostic pitfallsa review publication of the Radiological Society of North America, Inc. Radiographics. 2006;26 Suppl 1:S19-41.

20. Meckel S, Reisinger C, Bremerich J, Damm D, Wolbers M, Engelter S, et al. Cerebral venous thrombosis: diagnostic accuracy of combined, dynamic and static, contrast-enhanced 4D MR venography. AJNR Am J Neuroradiol. 2010;31(3):527-35.

21. Merriman L, Greaves M. Testing for thrombophilia: an evidencebased approach. Postgrad Med J. 2006;82(973):699-704.

22. Mackie I, Cooper P, Kitchen S. Quality assurance issues and interpretation of assays. Semin Hematol. 2007;44(2):114-25.

23. Goodwin AJ, Rosendaal FR, Kottke-Marchant K, Bovill EG. A review of the technical, diagnostic, and epidemiologic considerations for protein S assays. Arch Pathol Lab Med. 2002;126(11):1349-66.

24. Weimar C. Diagnosis and treatment of cerebral venous and sinus thrombosis. Curr Neurol Neurosci Rep. 2014;14(1):417.

25. Gao H, Yang BJ, Jin LP, Jia XF. Predisposing factors, diagnosis, treatment and prognosis of cerebral venous thrombosis during pregnancy and postpartum: a case-control study. Chin Med J (Engl). 2011;124(24):4198-204.

26. Murugappan A, Coplin WM, Al-Sadat AN, McAllen KJ, Schwamm LH, Wechsler LR, et al. Thrombolytic therapy of acute ischemic stroke during pregnancy. Neurology. 2006;66(5):768-70.

27. Stam J. Thrombosis of the cerebral veins and sinuses. $N$ Engl J Med. 2005;352(17):1791-8.

28. Chan KH, Cheung RT, Liu WM, Mak W, Ho SL. Cerebral venous thrombosis in a gentleman presenting with fever, convulsion and frontotemporal haemorrhages. J Clin Neurosci. 2005;12(2):186-8. 